\title{
Cooperation of a museum institution and students in creating virtual exhibitions using the MOVIO tool
}

\author{
Goran Zlodi, Josip Mihaljević, Anica Šimunec, Paula Mikeli, Ivana Rudić \\ Department of Information and Communication Sciences, \\ Faculty of Humanities and Social Sciences, University of Zagreb \\ Ivana Lučića 3, Zagreb, Croatia \\ gzlodi@ffzg.hr,jmihalje2@ffzg.hr, anica.simunec@gmail.com, \\ pmikeli@ffzg.hr, irudic@ffzg.hr
}

\section{Summary}

MOVIO is one of the creative tools from AthenaPlus network. Its purpose is to facilitate the creation of virtual exhibitions. MOVIO is very similar to other content management systems (CMS) but it focuses more on creating interactive multimedia page contents, such as digital photo galleries and exhibitions, games, interactive timelines, and digital storytellers. MOVIO tool provides and also shows how its different options can be easily and efficiently used by users who do not have any specific IT knowledge such as advanced programming or web design techniques, to create and show different types of virtual exhibitions. Virtual exhibition "For Better or Worse... / Wedding Fashion from 1865 till Present" is a virtual extension of a physical exhibition held in the Museum of Arts and Crafts in Zagreb. Virtual exhibition catalogue was developed using the Timeline tool as a page type which proved to be very effective in presenting the exhibition conceptualized chronologically. The Timeline allows easy browsing through virtual objects within the timeframe we have previously determined. The other virtual exhibition, "Herman Bollé - Builder of the Croatian Capital" is also a virtual extension of the real exhibition held in the Museum of Arts and Crafts. Using the MOVIO tool and information from the catalogue of the real exhibition, the virtual exhibition was made making the most MOVIO options. The FFZG team used the following page types Home Page, Page, Google Map, Storyteller and Timeline. Furthermore, Bolle's virtual exhibition has a unique content as compared to other exhibitions. It is an interactive game (among few simple puzzle and memory games) made in the Unity game engine which allows players to try to place many of Bolle's architecture designs and buildings on the appropriate location on the map. Tools like MOVIO show that technology has evolved and has become simplified for end users so that they can easily create virtual exhibitions production of which was complex or costly several years ago.

Keywords: virtual exhibition, multimedia content, interactive game, interactive timelines 


\section{Introduction}

The aim of the European founded project AthenaPlus is providing new tools to support cultural institutions to narrate their resources. These new tools where created by the Italian enterprise GruppoMeta on MOVIO platform which serves as innovative application for creating digital exhibitions and thematic routes. MOVIO offers different page templates that use different tools for showcasing digital content that can combine multiple media such as text, photo galleries, animations, timelines, games, Google map, and probably more content in the future. Layout of each of these pages is responsive, so it fits screens of all sizes and there is also multilingual support for creating content in many different languages (Minelli et al. 2015). This paper is a result of collaboration that was established between the Museum of Arts and Crafts in Zagreb and the Faculty of Humanities and Social Sciences in Zagreb. Museum of Arts and Crafts participates in the project AthenaPlus, whose goal is to upgrade the terminology and enhance the Europeana search engine. At the same time there is great emphasis on re-use of content and the development of tools and applications that support new possibilities of presenting cultural heritage. As part of the project, MOVIO tool for creating online digital exhibitions is in the developing process and several partners are testing the tool. Museum of Arts and Crafts created its own digital exhibition entitled "A Century of the Wristwatch" (http://54.247.69.120/ build/movio/movioTraining12) and furthermore, museum's staff (Petra Milovac and Iva Meštrović, curators) held a training on how to use the tool at the Faculty of Humanities and Social Sciences (course Virtual Museum, Goran Zlodi PhD, assistant professor). After the training, students tested the tool as well, creating two digital exhibitions: "For Better or Worse... / Wedding Clothes from 1865 to Nowadays" (http://54.247.69.120/build/movio/movioTraining39/) and "Herman Bollé - The Builder of the Croatian Capital" (http://54.247.69.120/ build/movio/movioTraining40/en/). In this paper authors will present their experiences of creating online virtual exhibitions with the MOVIO tool.

\section{MOVIO - online virtual exhibitions}

MOVIO is one of the creative tools from AthenaPlus network. Its purpose is to facilitate the creation of virtual exhibitions (athenaplus.eu). MOVIO is very similar to other content management systems (CMS) for creating websites such as WordPress and Joomla!, but it focuses more on creating interactive multimedia page contents, such as digital photo galleries and exhibitions, games, interactive timelines, and digital storytellers. Most of MOVIO's functions are intended for presenting the content of museums and galleries in a variety of ways. For example, Partenon frieze is a part of a plaster cast of ancient sculptures at the Faculty of Humanities and Social Sciences of the University of Zagreb. It can be shown as a simple photo gallery with a slider for images, as a storyteller or a timeline, where each part of the frieze is chronologically explained with images and texts (wiki.athenaplus.eu). 


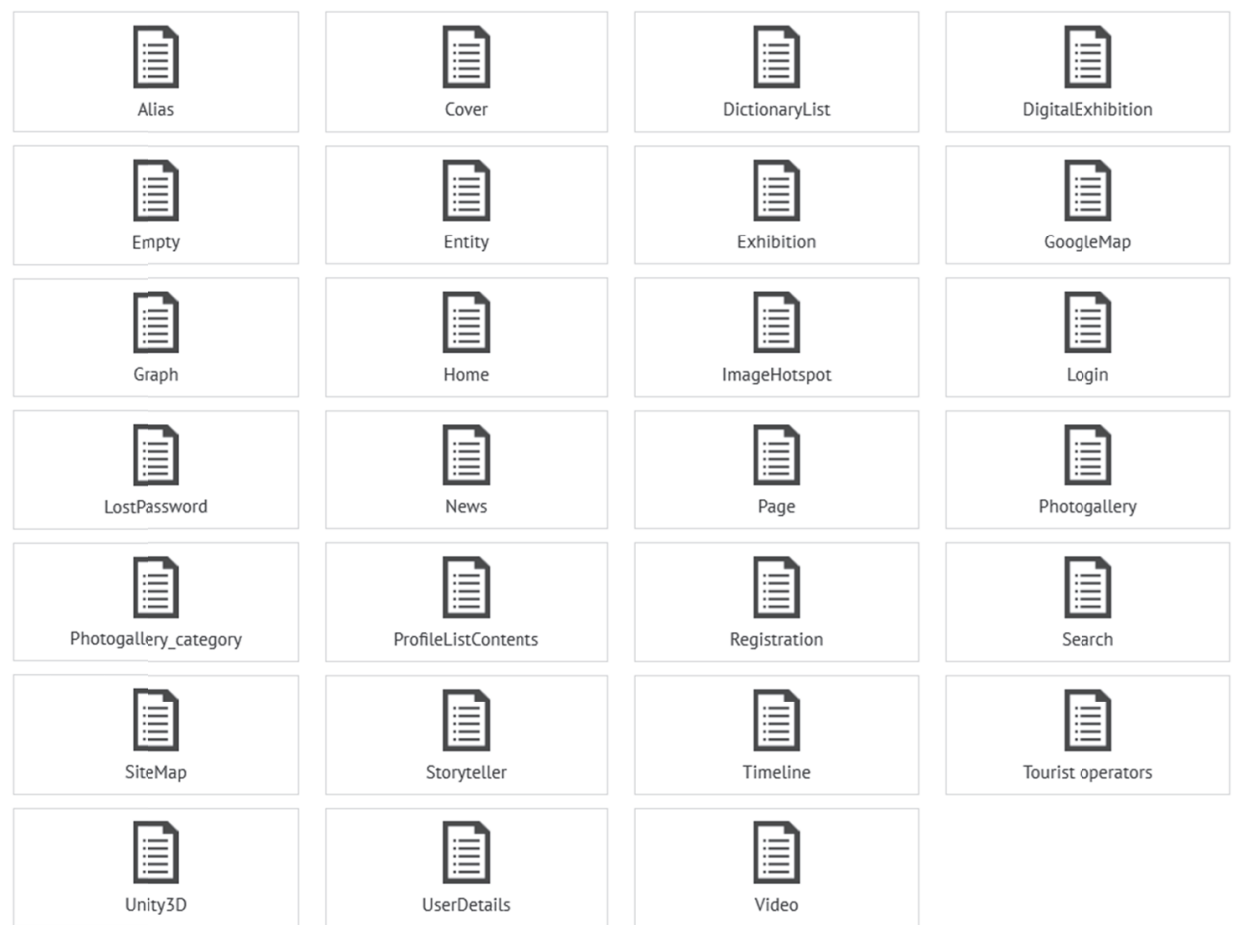

Figure 1. Different types of page contents available with MOVIO

Only users with a username and a password can access the back-end interface. The administrator can create multiple accounts for other people to enter and create site content. However, only the administrator has the right to delete pages, hide them from visitors or change them to private. The back-end is the area for the Ontology and Content Management of MOVIO. It consists of three sections:

A. The section with the list of items on which it is possible to work in the back-end;

B. The section with the index of the structure of pages;

C. The section to create and edit the page content and the ontology structure.

$\mathrm{B}$ section is a list of created pages in a MOVIO instance. The Home page from which others originate is always on the top. Underneath it there are three predefined folders Metanavigation, Footer and Utility. Other pages and folders are created by the user or administrator. Pages can be rearranged via drag and drop: the user simply selects a page and drags it to the desired position. Pages can also be nested one into the other to create better site structure (wiki. athenaplus.eu). The CMS system allows its users to edit page content, therefore each page type can be changed, including its text and media. MOVIO uses 
WYSIWYG (What You See Is What You Get) text editor, which is very similar to text editors that are mostly used on web forums. It has basic text formatting buttons such as bold and italic, text alignment buttons, citation button, undo and redo buttons, insert symbol button, hyperlink button, insert table button, anchor button, image button, and a HTML button which allows coding in the editor (wiki.athenaplus.eu).

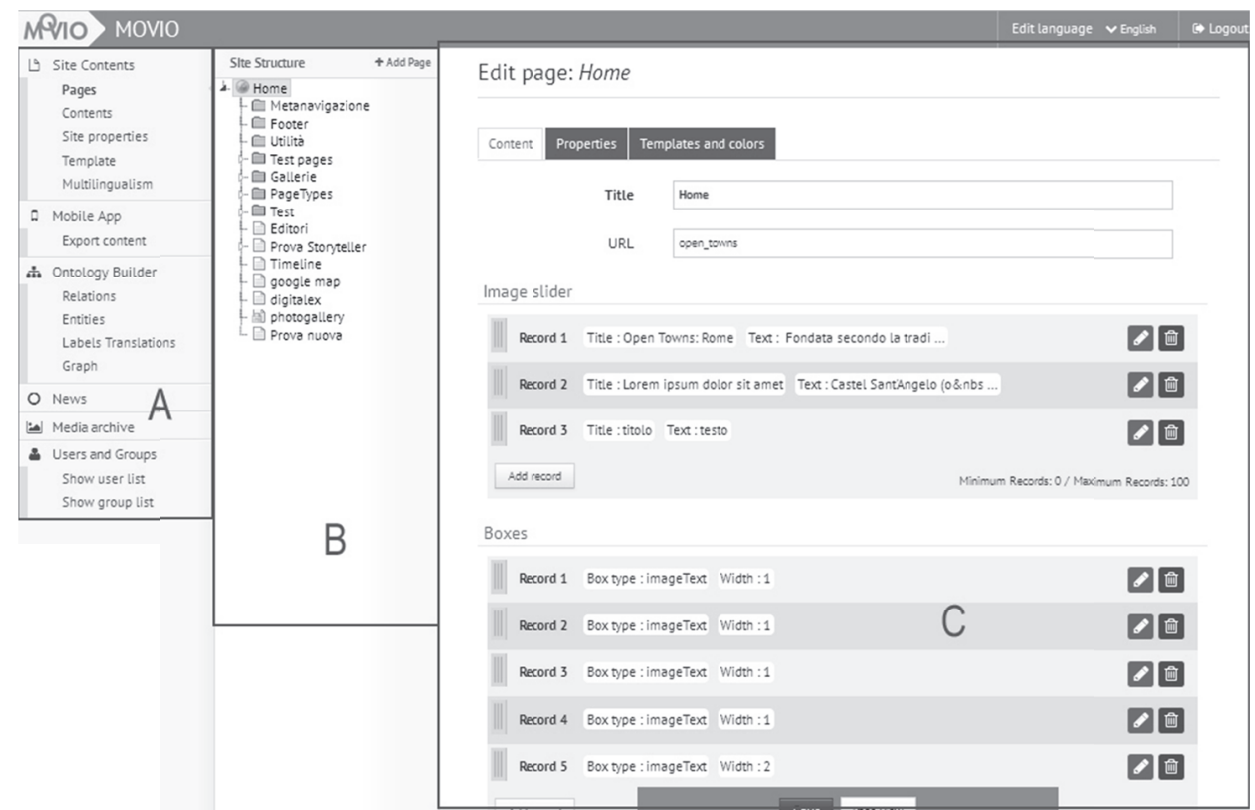

Figure 2. Three sections of MOVIO back-end

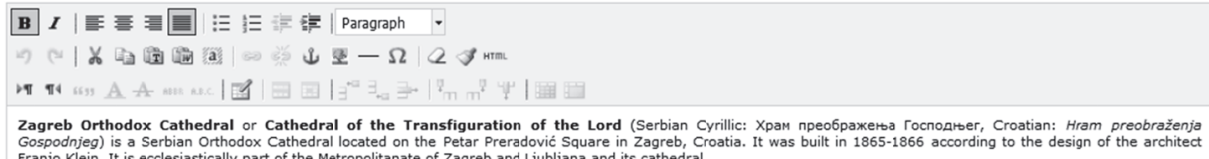

Zagreb Orthodox Cathedral or Cathedral of the Transfiguration of the Lord (Serbian Cyrillic: Xpam npeo6paweњa rocnopњer, Croatian: Hram preobraženja Franjo Klein. It is ecclesiastically part of the Metropolitanate of Zagreb anc Ljubljana and its cathedral.

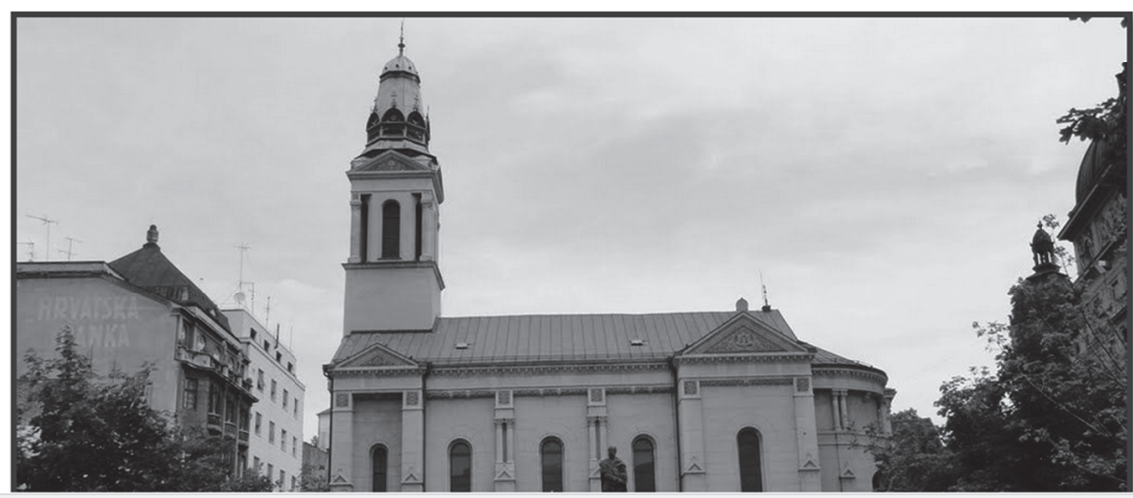


One of the very important characteristics of MOVIO is the possibility to add an unlimited number of new languages, and choose the default one. Enabled languages are always shown on the right hand side of the top bar of MOVIO in the back-end. When a page is displayed on the front-end part, language options are switched to the left side of the top bar. When creating content for multiple pages, it is important to have in mind which language is set as the default - one should always create new content in the default language, and MOVIO will transfer the content to other languages automatically. Author then only has to translate the texts to other languages (wiki.athenaplus.eu). The back-end part of MOVIO has one part for the management of multimedia objects in the system called Media Archive. Media Archive stores and organizes multimedia content such as images, audio and video files, PDF and Word documents, as well as Unity game extensions for future use. When the user uploads content to the Media Archive, he can add metadata such as author, category, date, copyright type, and description. There is also an option which allows zooming and downloading of pictures and the insertion of the watermark option. After media is uploaded in the archive, it can be used for creating pages. Finding the required item in the Media Archive is facilitated by the search bar that allows filtering based on file metadata such as author, title, file name, category, and even description. Users can also filter content based on the type of the media (wiki. athenaplus.eu).

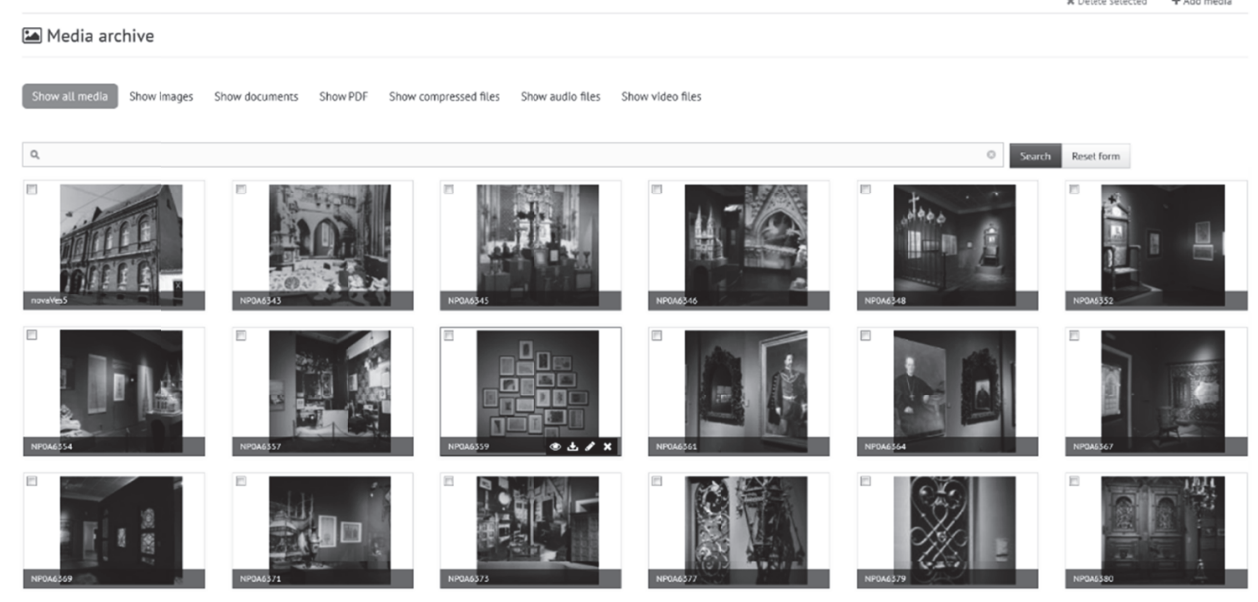

Figure 4. Media archive interface

Speaking of various MOVIO services, the creators strongly feel that the Ontology Builder function/tool is one with the most potential. The Ontology Builder can be used as a solution for displaying the content of a virtual exhibition in a non-linear way. Entities of artists, artwork, and the departments of the University, as well as the relations between them were developed with this tool/ function (Minelli et al. 2015). 


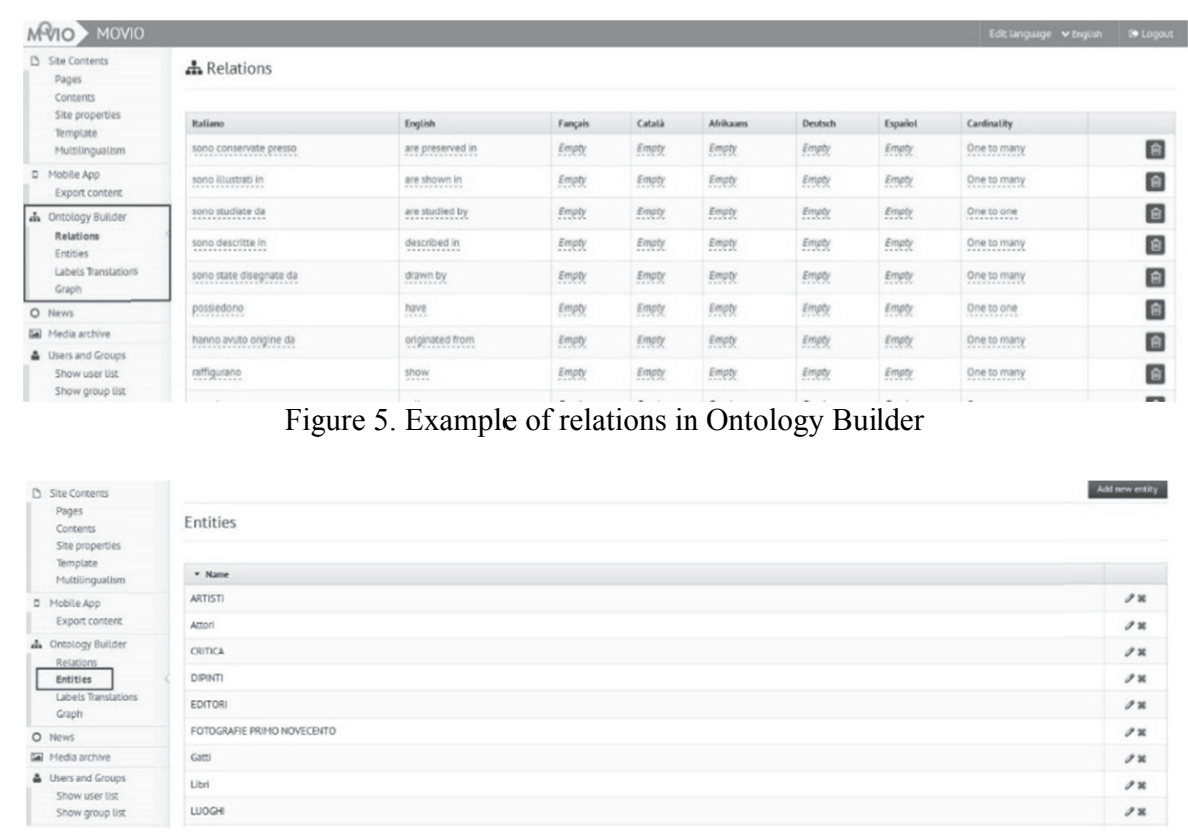

Figure 6. Example of entity in the Ontology Builder

\section{Entità - Artista}

PAROLA DA RICERCARE

CERCA RESET

\section{Risultati della ricerca}

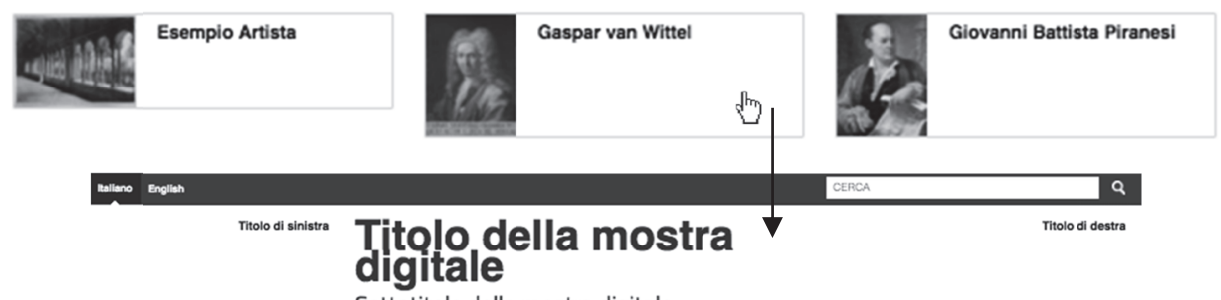

Sottotitolo della mostra digitale

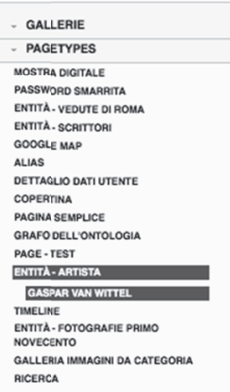

Percorso: Home o PageTypes , Entitä - Arista , Gaspar van Wettel

\section{Gaspar van Wittel}

Vanvitelli

Nome Gaspar

Cognome van Witel

Data di nascita e morte 1653-1736

Biografia

In patria fu allievo di Jan van der Heyden, Gerrti Berckheyde e Matthias Withoos dal 1669 circa al 1674, anno in oui sit tasteti in taja[1], Risiodeva a Roma, spde di una nutrta colonia di pittor olandesi. Nel 1675 collaboro con lingegnere Cornelis Meyer per effettuare i rilievi grafici de corso del Tevere: il gusto per il dettaglio e limpostazione descrittiva e tersa tipici del vecutismo nordico carattorizzeranno la sua produzione, dedicata a ritrarte Roma o le sponde cittadino de Tevere. Ottenne tali risutati anche grazie ad alcuni strumenti giâ usati dai vecutisti cel nord come la "scatola ottica"

Figure 7. Example of using the created ontology for searching content (wiki.athenaplus.eu) 


\section{Case Studies}

\section{Virtual exhibition "For Better or Worse... - Wedding Clothing since 1865 until Nowadays"}

Virtual exhibition "For Better or Worse... - Wedding Clothes from 1865 to Nowadays" is a virtual extension of the temporary exhibition held in the Museum of Arts and Crafts in Zagreb from February to May 2015 (author: Andrea Klobučar, senior curator). Virtual exhibition catalogue was developedl using the MOVIO Timeline tool which proved to be very effective in presenting the exhibition conceptualized chronologically.

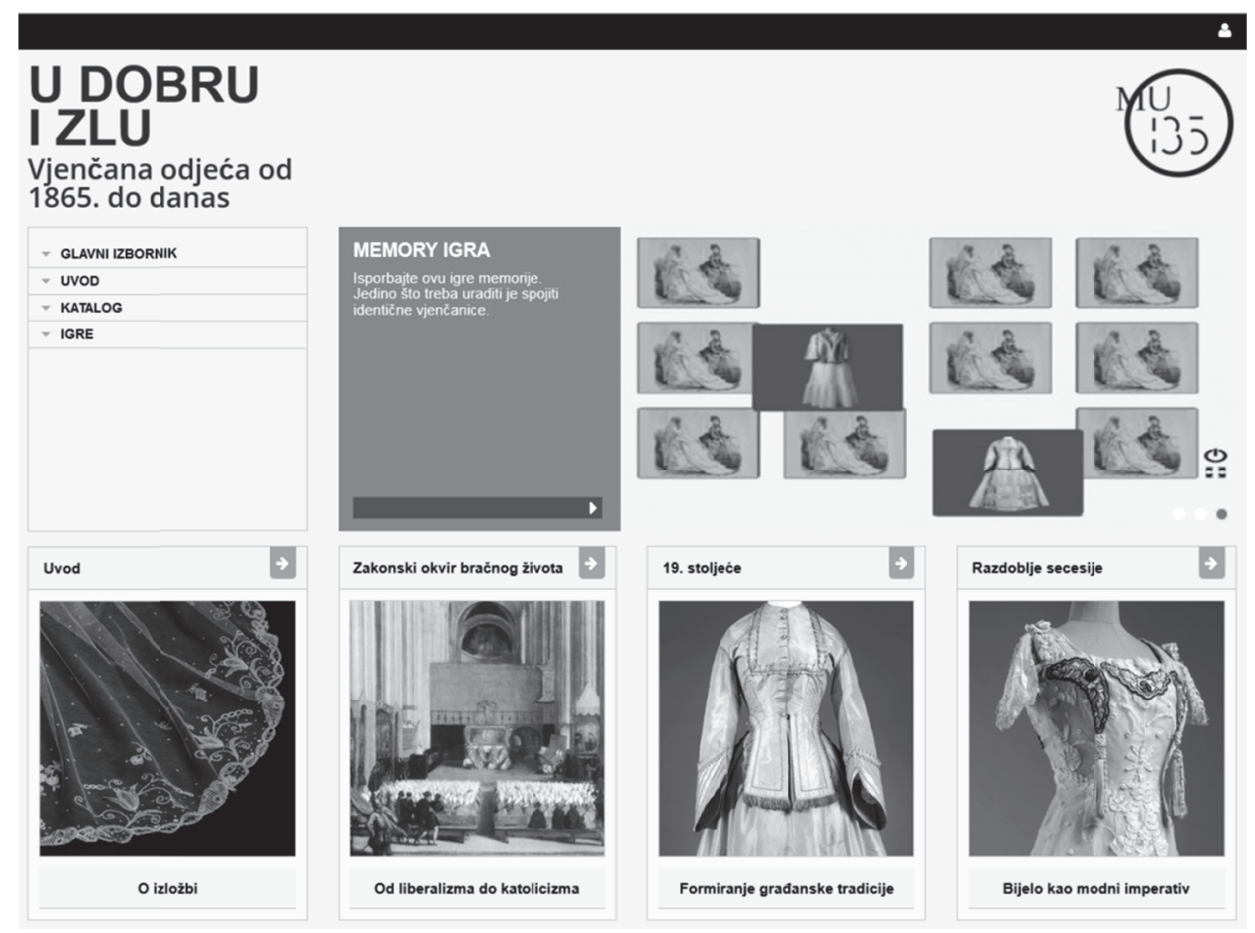

Figure 8. Home page

Timeline allows easy browsing through virtual objects within previously determined timeline. During the development of the timeline, a time period was selected, within which the objects were located automatically and chronologically, depending on the year, month or day assigned to them. For every entered record, MOVIO allows contents: text, images, videos, etc. (wiki.athenaplus.eu). If the content exceeds the provided space for object presentation, in the front-end on the left, a scroll bar automatically appears - this allows the rest of the page to remain static, while the presentation space scrolls up or down. In the front-end, MOVIO tool allows browsing using pointers (left or right), but the user can also 
select the exact object he is interested in on the timeline, which is always presented beneath the presentation space. If, however, the user decides to use pointers to navigate left or right, bellow every pointer the heading of the following virtual object is written, which makes browsing easier. MOVIO tool also enables zooming in or zooming out the timeline, which allows the user to enlarge records and see them more clearly or make them appear smaller but more numerous. In the virtual exhibition "For Better or for Worse - Wedding Fashion from 1865 till Present" the main timeline of this exhibition spans over 150 years and it is divided chronologically into shorter periods of a few decades or even less. For example, within those 150 years there are periods such as 19th century wedding clothing, Art Nouveau period, Inter-war period, etc. By clicking on the preferred period another timeline opens in which the objects are again chronologically presented with pictures and a short text. The Timeline allows an excellent overview of a chronologically designed exhibition and the tool is able to do a great part of the work by itself. The user only has to enter the content and determine the timeframe within which the presentation will be made, which makes this tool easy to use. The FFZG team suggested the expansion of the number of records for the Timeline tool. Also, there is a team working at the Museum. However, currently there is a team working in the Museum of Arts and Crafts that reports all current mistakes, bugs and possible improvements to the AthenaPlus network. The programmers from the GruppoMeta are fixing the issues and working on the improvement of the tool.
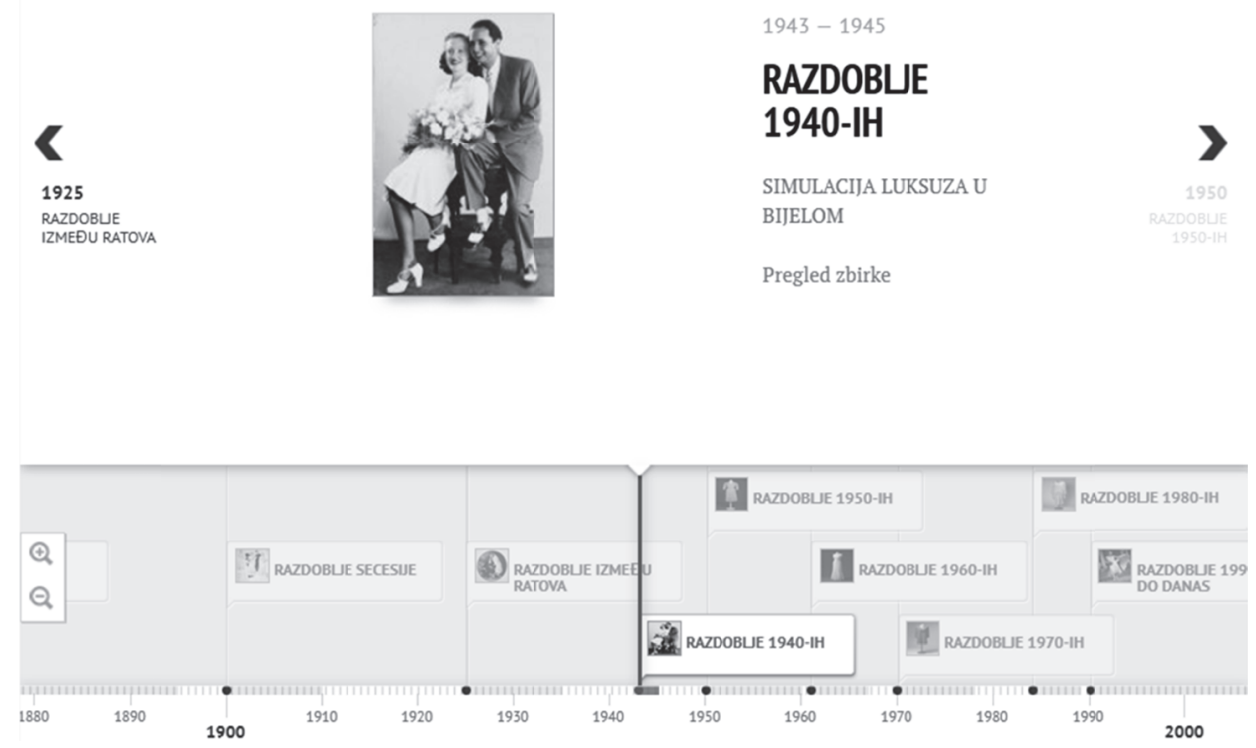

Figure 9. The Timeline 


\section{Virtual exhibition "Herman Bollé - Builder of the Croatian Capital"}

Virtual exhibition "Herman Bollé - Builder of the Croatian Capital" is a virtual extension of the real exhibition held in the Museum of Arts and Crafts in Zagreb from April to August 2015 (author: Dragan Damjanović PhD, associate professor). Using the MOVIO tool and information from the catalogue of the MUO temporary exhibition the Faculty of Humanities and Social Sciences team of students created the virtual exhibition. The team tried to make the most of this tool, so they used various different page types such as Home Page, Page, Google Map, Storyteller and Timeline. All page types have common features which are Title and URL, and differ in specific features unique for every page type. In this chapter we will explain the possibilities of these pages and share our experience with each of them.

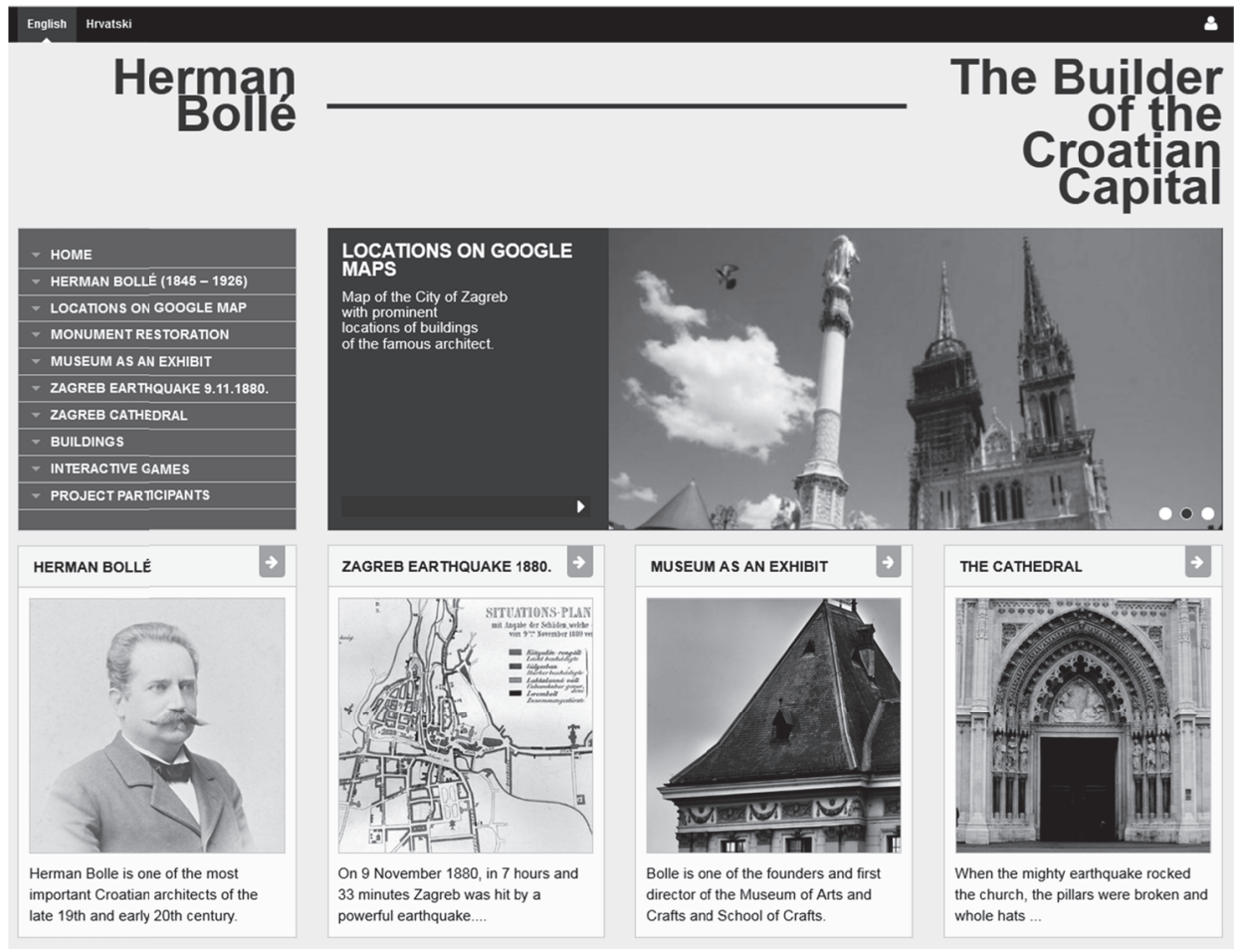

Figure 10. Home page

The Homepage Page Type created in MOVIO allows the creation of a page consisting of a title, one or more Sliders and one or more Boxes. A new Home Page Type is created by selecting Home from the menu Page Types (wiki. athenaplus.eu). For the Slider of the homepage the user can add a title, text, an 
image and a reference to one of the pages in the MOVIO exhibition. For the homepage of the exhibition the team created three slides (Timeline, Locations on Google maps and Herman Bollé - Builder of the Croatian Capital), each of them having a reference to a specific page of the exhibition, image, and a short introductory text.

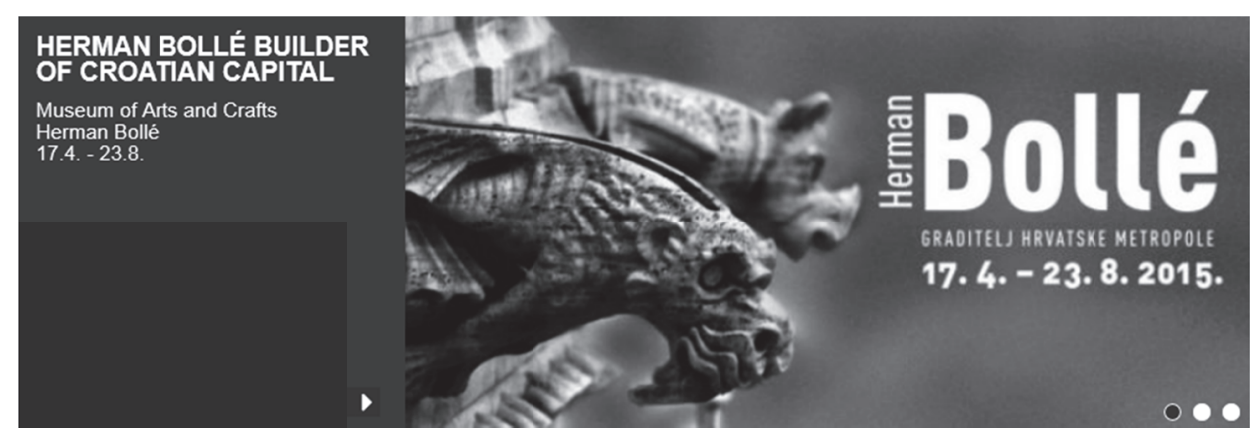

Figure 11. Homepage slider

A Box is an element which is able to host two different types of media combinations: an image with the text or an image with a link. The team created seven boxes, all of them contain an image, a short text and a link. Links of boxes lead to main themes of the exhibition which are: Herman Bolle, Zagreb Earthquake, Zagreb Cathedral, Museum as an Exhibit, Location on Google Maps, Buildings and the Interactive Game.
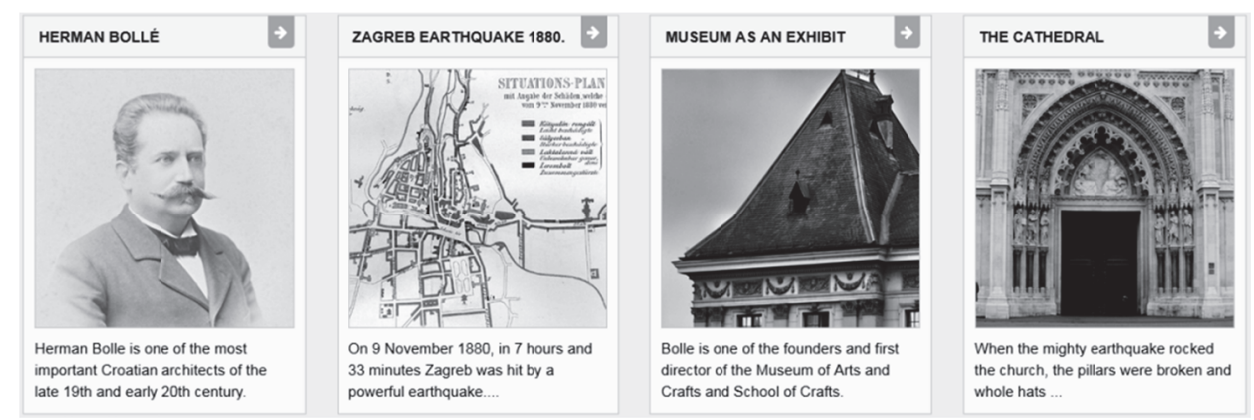

Figure 12. Boxes

\section{Page type: Page}

The Page Type Page allows creation of a classic page for a website, a page that can be composed of a title, text, a sequence of images, and a sequence of attachments (wiki.athenaplus.eu). This page type was most useful in creating this virtual exhibition and the most comprehensive part of it. The team used this page type in the process of creating main themes (Zagreb Earthquake, Zagreb Cathedral, Museum as an Exhibit and Buildings) and their subtopics. As the 
basic source of information the team selected the catalogue of the real exhibition and relevant secondary sources as well as popular web pages with information about buildings and events. The team used all of the possibilities provided by this page type.

\section{Page type: Timeline}

Since the possibilities of the page type Timeline have already been described in this study, this part of the article will focus on the team's experience. The timeline of the exhibition represents the life of Herman Bollé and his work. The team has set up six timelines, which cover the time period from 1845 to 1926. Each item of a specific Timeline has an image, a short text and a date.

\section{Page type: GoogleMap}

The GoogleMap Page Type allows the Point of Interest (POI) to be graphically displayed on a map. The tool Google Maps used in MOVIO is a Google service (developers.google.com/maps/). In particular, the interactive geographic maps use the following library: http://hpneo.github.com/gmaps/ (wiki.athemaplus.eu). This page type was very useful for the exhibition - it enabled the tean to represent the work of an architect whose buildings spread across Zagreb. The team did not include buildings that were not in Zagreb. The map has 29 locations, each of them has an image and a title. Adding locations on the Google maps with MOVIO is done with Markers, which are composed of POI and texts (address and name of the building).

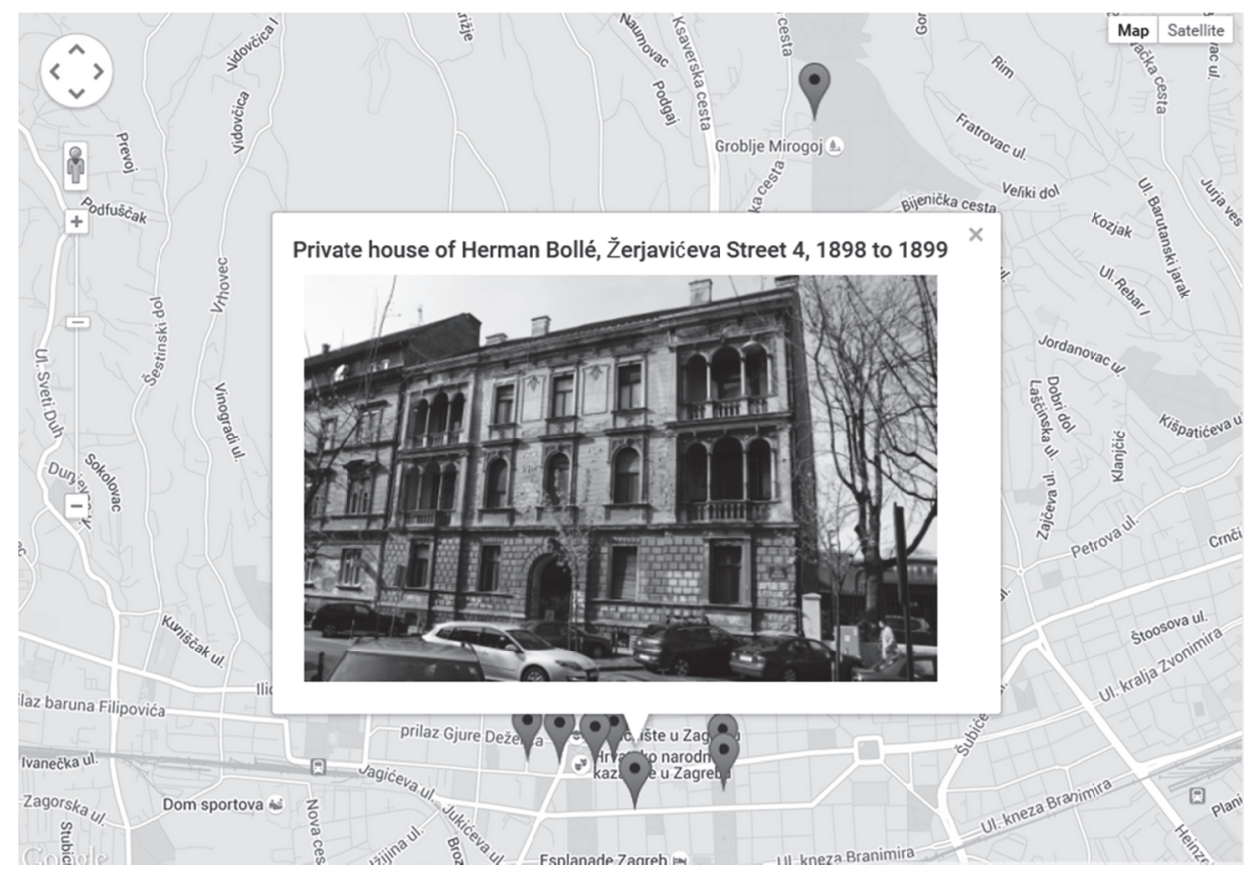

Figure 13. Google maps 


\section{Interactive game}

In addition to the functions available in MOVIO, in for this exhibition a member of the team has integrated additional content. It is an interactive game (http://54.247.69.120/build/movio/movioTraining40/?pageId=89) which allows players to attempt placing many of Bollé's architecture designs and buildings to appropriate locations on the map. The game was originally planned as an interactive map made with the ImageHotspot page template, but the team realized that it would be better to seize the opportunity of the content and create a simple, but interesting and effective, drag and drop game. The Game is made in the Unity game engine because MOVIO supports Unity. The map with the locations was given to students as one of the referential materials for creating site content. It was the perfect material for a drag and drop game although that was not its original purpose. Because all buildings and architecture designs where shaped as round circles with the exact same size, they could easily be cropped as a piece that can be placed on any of the locations.

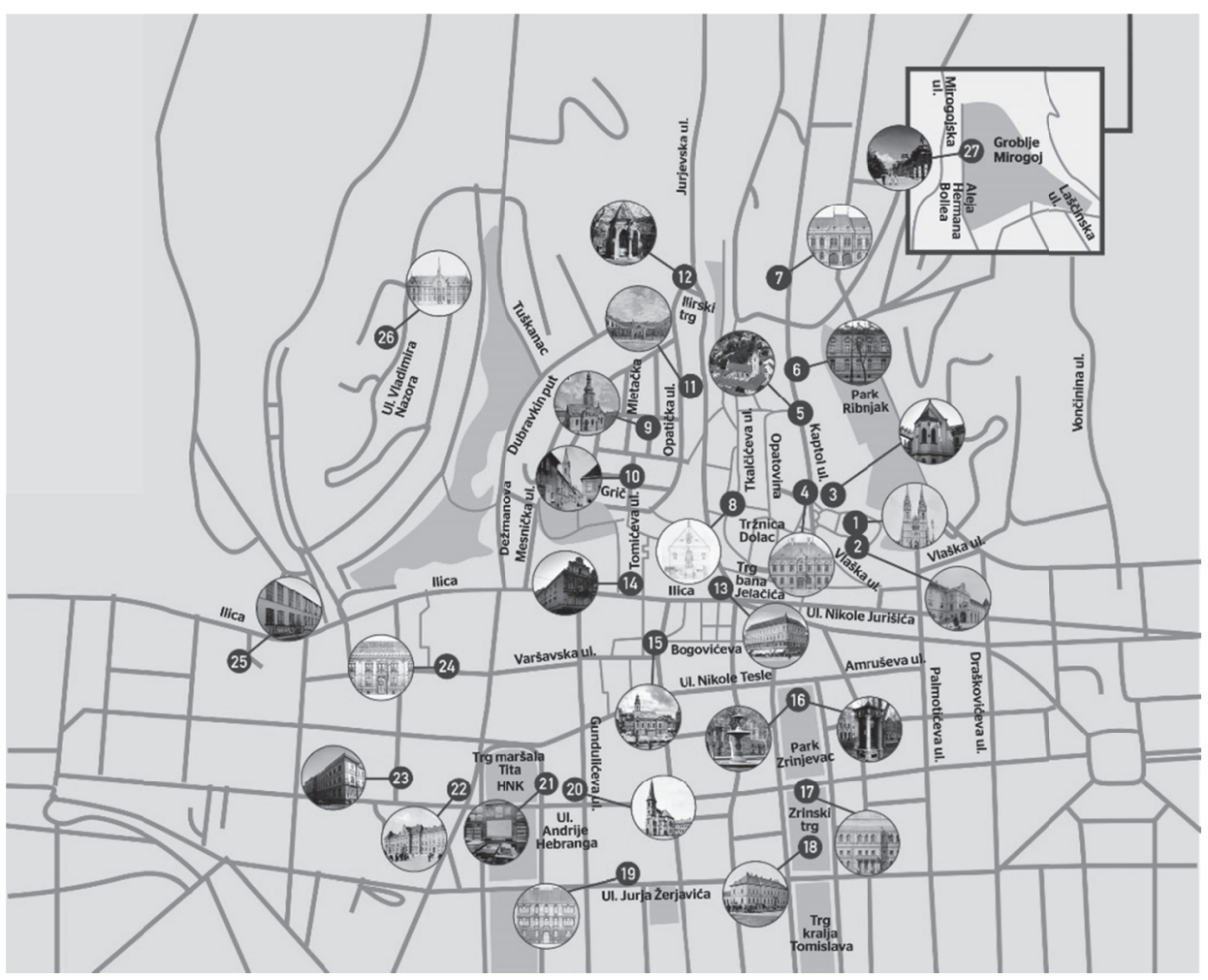

Figure 14. The map used for the interactive game 
There are 28 building that where cropped from the map using a free and opensource raster graphics editor GIMP. Each of the cropped buildings was saved as a small JPEG image that was later imported as an asset into the Unity game engine along with the map with empty round-shaped spaces in which the buildings were to be inserted. Each asset in Unity has its own code which defines the actions that the user will have if he moves one of the objects with a mouse or drags it on a touch screen. If the player guesses the approximate position of the location of the building, it sticks to that location. This game is interesting because it is educational and meant for players who do not know much about certain building locations. Most of the adults in Zagreb recognize the buildings but are not sure where they are positioned. It is also more complex than common drag and drop games because there are 28 locations for which the user should know the exact location. While similar children games are composed of less objects, this game requires more time and certain geographic memory, therefore it is more appropriate for adults. Regardless of this fact, children can also easily play it and learn about some culturally relevant locations on the map such as St. Mark's Church and the Zagreb Cathedral. If the player is not sure where a certain location is, he or she can simply click the Solution button which places all buildings in the correct place. The game is functional but it could be updated in the future by designing better user interface and adding solutions for one location at a time. There is also a problem that Unity has with browsers, since it requires the installation of the Unity web player plug-in to work with a certain browser. MOVIO tool does not support the more widely used Flash plug-in and it does not have options to support HTML5 games which would work equally well on all browsers and platforms without the need for additional plug-in installation. However, with future updates such options will probably become possible. This interactive game can be used as an example of how easy it is to create interesting and simple multimedia content by using only programming tools that are free.

\section{Conclusion}

Tools like MOVIO show that technology has evolved and has been simplified for end users so that they can easily create virtual exhibitions that were just few years ago too complicated even for expert programmers. With MOVIO tool archives, museums and libraries can create rich and interactive multimedia content for presentation of their assets. This article also shows that usage of contemporary information and communication technology tools like MOVIO gives new opportunities of cooperation between cultural heritage institutions and university students what could result in benefits for both parts and, what is most important, benefits for end users. 


\section{References}

ATHENA Plus - Access to Cultural Heritage Networks for Europeana. http://www.athenaplus.eu/ $(2015 / 06 / 25)$

Athena plus wiki. The media archive. 15 April 2014. http://wiki.athenaplus.eu/index.php/The media archive $(2015 / 06 / 25)$

Athena plus wiki. Multilingualism in MOVIO. 21 April 2014. http://wiki.athenaplus.eu/index. php/Multilingualism_in_MOVIO (2015/06/25)

Athena plus wiki. The WYSIWYG text editor. 21 April 2014. http://wiki.athenaplus.eu/index. php/The_WYSIWYG_text_editor (2015/06/25)

Athena plus wiki. PageType: Timeline. 21 April 2014. http://wiki.athenaplus.eu/index. php/MOVIO_Pagetype:_Timeline (2015/06/21)

Athena plus wiki. PageType: Google Map. 21 April 2014. http://wiki.athenaplus.eu/index. php/MOVIO_Pagetype:_Google_Map (2015/06/30)

Athena plus wiki. PageType: Page Map. 21 April 2014. http://wiki.athenaplus.eu/index. php/MOVIO_Pagetype:_Homepage (2015/06/30)

Athena plus wiki. PageType: Home Page Map. 21 April 2014. http://wiki.athenaplus.eu/index. php/MOVIO_Pagetype:_Page (2015/06/30)

Athena plus wiki. Introduction to MOVIO back-end. 2 June 2014. http://wiki.athenaplus.eu/ index.php?title=Introduction_to_MOVIO_back-end (2015/06/25)

Meštrović, I. (2015). Digital and Virtual Exhibitions - A Glance at the Situation in Croatia. UncommonCulture: Virtual Exhibitions. 6(1): 114-119.

Minelli, Habibi, S., Meštrović, I., Milovac, P., et al.

(2015). Museums' Experiences in Creating Cultural Narrations Using the AthenaPlus Tool Called MOVIO. Uncommon Culture 6(11): 67-87. 